\title{
A Model of Indicators and GIS Maps for the Assessment of Water Resources
}

\author{
Khandaker Iftekharul Islam ${ }^{1,2}$ \\ ${ }^{1}$ Department of Civil Engineering, IUBAT University, Dhaka, Bangladesh \\ ${ }^{2}$ Chalmers University of Technology, Sweden \\ Email: iftikhar@alumni.chalmers.se
}

Received 26 May 2015; accepted 30 August 2015; published 4 September 2015

Copyright (C) 2015 by author and Scientific Research Publishing Inc.

This work is licensed under the Creative Commons Attribution International License (CC BY). http://creativecommons.org/licenses/by/4.0/

(c) (i) Open Access

\section{Abstract}

The main intention of the study is to identify appropriate indicator to create a model that represents water resource status for a specific system boundary. The report will assess the different scientific approaches associated with water resource engineering, and compare these approaches with respect to human value. The report will focus on the relationship between ecosystem structure and socio technical structure. Ecosystem deals with plants and living things in specific area and the interaction between them, socio technical system deals with the aspects of people, and society as well as technical aspects of organizational structure with respect to the effect on the environment. Ecosystem directly or indirectly affects the society. At the same time, the socio technical system has an impact on ecosystem services in the perspective of consumption and exploitation of recourses. Finally the two systems are dependent on each other. By the application of scientific tools such as Life Cycle Assessment (LCA), Environmental Impact Assessment (EIA), Environmental Risk Assessment (ERA), Performance Indicator (PI), Drivers Pressure State Impact Response (DPSIR), Mellenium Ecosystem Assessment (MEA), etc., some appropriate indicators can be identified corresponding to each approach. LCA focuses on socio-technical aspects whereas DPSIR is environmentally biased. Environmental impact assessment covers both aspects of the system. A matrix combines these methods with the corresponding keywords, and supports in generating a new general model by considering the most weighted indicators. Since each scientific model focuses on some specific aspects, the newly proposed model will give a general view of water environment status. A final comparison is made to recognize relative bias of the newly proposed model with respect to DPSIR model to assess water environment status of the concerning region.

\section{Keywords}

Water Resource Assessment, Ecosystem, Socia Technical System 


\section{Introduction}

At the beginning of this new decade, it has been a great concern to evaluate the state of water resources of the world. Water resources are the main source of fresh water, providing valuable ecosystem services to society, living organisms, plants and environment [1]. Environmental deterioration due to population growth, expansion of business activity, rapid urbanization, climate change and depletion of aquifers, makes water resources more vulnerable. During $20^{\text {th }}$ century, 50 percent wetlands of the world have been identified which degraded intensively and became unable to provide their valuable ecosystem services [2]. These days, awareness has been developed to preserve water for ecosystem services. The need for a systematic process of evaluation to evaluate water resource and environmental status has been recognized for last few decades. Since then the use of some developed methods spread throughout the world which have been adapted to assess environmental impact. These methods focus on the impacts through some indicators. A model is constructed from indicators and these indicators are generated from keywords. These models which consist of the indicators are biased either environmentally or socio technically. The model which is biased environmentally reflects socio technical aspects less than environmental aspects while the model biased socio technically considers socio technical factors more. The need to a contemporary model to access neutrally has been perceived. The main intention is to select a set of indicators in order to make a general model to appraise the state of water resources and environment.

A model derived from a set of keywords represents the way of evaluation. These keywords are generated from scientific theory. The keywords turn into indicators which show the state or condition. So, appropriate indicators are to be selected to construct a model, to evaluate the water and environmental status. The main objective of the report is to identify appropriate indictors in order to create a model which evaluates the water resource status, and also provide GIS maps to support decision making to different stakeholders. Different sort of indicators are chosen reviewing recognized scientific methods. Seven scientific tools are analyzed in choosing these indicators. These are Life Cycle Assessment, Environmental Risk Assessment, Environmental Impact Assessment, Performance Indicator, Millennium Ecosystem Assessment, the DPSIR (Drivers Pressure State Impact Response), and Material Flow Analysis. Each method produces a model based on its own theory. This model shows the different indicators dividing by two categories i.e. ecosystem and socio technical system. A matrix aggregates all the methods with corresponding indicators. A general model is derived from the accumulated keywords. A matrix combines these keywords which have been considered in each of the methods. This newly proposed model will be formed by assimilating most weighted keywords of the matrix under ecosystem and socio technical system. The model will focus on the relationship between ecosystem and socio technical system with respect to human value. A comparison between a newly formed general model and a well established model shows the relative bias of the new model. The drawbacks regarding the model might be fixed by this. GIS maps are produced depending on the selected indicators. The concerning project deals with the Götaälv river located in the second biggest city of Sweden, Göteborg. The river is used for several purposes in the city. Some of the main purposes are drinking water and hydropower.

\section{Literature Review}

Environmental system analysis consists of various concepts and assessment tools. These tools facilitate of achieving a sustainable environment assessing all relevant parameters. These concepts are diversified into different disciplines and different purposes. But the common principle is to identify the key factors influencing the ecosystem and socio technical system with respect to human value. And these key factors are revealed through indicators. The ecosystem assessment deals with environment based effect considering the value of all living organisms and non-living things in specific area. On the other hand, socio technical system assessed social aspects of people and society, and also technical aspects of organizational structure. Then the relationship between two cases and keywords regarding water resource management is summarized in Figure 1.

To get a clear idea of whole ecosystem and socio technical system within the system boundary, these keywords are studied. The studies are done under different methods. This study of this individual method is divided into two parts. The first part contains a discussion about the process outlining aim, performance, drawback, contents and methodology. In the second part, a conceptual model is generated from aggregated keywords.

Eight keywords which belong to ecosystem services and socio technical services are described. To get a clear idea of whole ecosystem and socio technical system within the system boundary, these keywords are studied. The studies are conducted under different methods. This study of individual method is divided into two parts. 


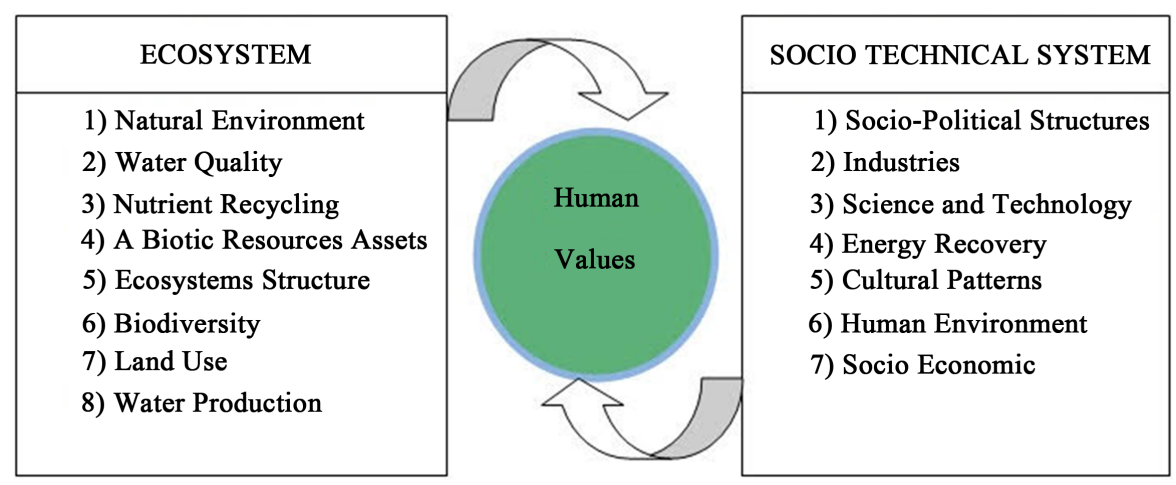

Figure 1. Aggregation of various possible key words within two systems.

The first part contains a discussion about the process outlining aim, performance, drawback, contents and methodology. In the second part, a conceptual model is generated from aggregated keywords. The methods that are analyzed include Life Cycle Assessment, Environmental Impact Assessment, Risk Assessment, Material Flow Analysis, Performance Indicator, and the DPSIR (Driving Pressure State Impacts and Response). The main intention is to form a contemporary model with respect to each method. These models will show the key factors corresponding to each method.

\subsection{A Life Cycle Assessment (LCA) Based Model}

Life Cycle Assessment based model shows keywords focusing on both socio technical and ecological aspects related to integrated water resource management with regard to human value; it considers all environmental impacts associated with integrated water resource management. Various indicators are also considered on its way of approach. It is applied for evaluating and quantifying environmental impacts of a product or service from cradle to grave throughout the life path of a product from extraction of resources to production, use, and endof-life caused by its existence [3]. Life cycle assessment considers water quality as one of the indicators originated from water resources, wastes, and pollutants. The main principle for considering water quality in impact categories is that the water sources are impaired by human activities. Land uses another resource impact category in LCA. Land is an important resource; it is relevant to include land use. Soil erosion, soil organic matter, soil structure, soil pH, phosphorus and potassium status of the soil are some examples of indicators regarding land use. LCA shows the significance of nutrient recycling and energy recovery. In case of urban water system, the starting point of LCA is withdrawal of water from ground and surface water and the ending point is discharge of treated storm and waste water. Drinking water treatment and waste water treatment, technical and surrounding agricultural issues are included in the system. Water quality indicators and nutrient recycling represents ecosystem structure while socio technical system is covering, science and technology, energy recovery, natural resource and industries etc. Life cycle assessment (LCA) in both cases works with some limited system boundary and relationship to human values showing bias a bit towards environment. Some particular keywords from Figure 1 are focused in LCA concept. Following Figure 2 represents LCA based model.

\subsection{An Environmental Impact Assessment (EIA) Based Model}

Environmental Impact Assessment is intended to identify and predict the impact from the project of water resource management to environment, human health, and living being. Interpreting information about the impact, EIA analyze, alternate the process, provide solution or mitigate the negative impacts on environment, human and living thing. EIA is an effective way of improving stakeholder involvement in environmental decision making and it offers a systematic way of dealing with conflicting points of analysis [3]. EIA is always necessary when industries are constructed or during the expansion of existing capacity. EIA mainly focus in avoiding disturbance against environment and natural resource assets before occurring or before implementing the project. EIA considers the impact on water resources, which are threatened by different projects, pollutants and wastes disposed from industries. Water quality is one of the significant ecosystem services which come from these sources. The EIA recognizes exercises which have potential effects on water quality and also recommends some 


\begin{tabular}{|c|c|c|}
\hline \multicolumn{2}{|l|}{ Ecosystem } & Socio technical System \\
\hline \multicolumn{2}{|l|}{ Natural Environment } & Industries \\
\hline Nutrient Recycle & \multirow{2}{*}{ Human value } & Science and Technology \\
\hline \multirow[t]{2}{*}{ Water Quality } & & Energy Recovery \\
\hline & & Natural Resource \\
\hline
\end{tabular}

Figure 2. Chosen indicators for LCA based model within ecosystem and socio technical system.

mitigative measures toadjust the effects connected with the project. Land is another resource which is considered in EIA as an impact category. Soil degradation, soil acidification, alkalization can take place during construction phase associated with the project. Environment is unavoidable part at this moment which needs to be considered in any project. It must be addressed during project planning phase. As an integrated of a project EIA also covers economic, institutional, socio political and technical aspects. As an integrated part of water resource management, EIA figures out the keywords into ecosystem and socio technical system. EIA considers especially economic aspects of society before implementing a project. Environment impact assessment (EIA) in both cases (ecosystem and socio technical system) works with the relationship of human values. The following Figure 3 shows EIA based model.

\subsection{An Environmental Risk Assessment (ERA) Based Model}

Ecological Risk Assessment focuses on all living things other than human, which includes plant and animal. These fauna and flora have direct contact with the quality of water. Water resources are the source of water which has indirect contact with agricultural activities and land use. Different types of fertilizer used in agricultural activities are mixed with runoff water and go into the water resources. The hazard of water quality will affect the Environment in the way of drinking water, safe food, and other ecological services. Industrial productions requiring the use of water generally produce and directly dispose wastewater into the river and affect the surface water, and finally affect Environment and ecosystem. Risk assessment always deals with the less consequence to technical system, socio economic system, and ecosystem. It focuses to ensure reliability in a wide range of environmental issues, including utilization of natural resources and ecological preservation and public health considerations [4]. Environment risk assessment (ERA) approaches water quality, land use, human environment and socio economic aspects which are figured out as keywords into Ecosystem and socio technical system. Environment risk assessment (ERA) in both cases works with the relationship of human values and the outcome risk to the society. And Figure 4 represents the model.

\subsection{A Performance Indicator Based Model}

Environmental performance indicator is a critical tool used to define, reviewing and evaluate environmental performance of organizations in terms of progressing towards its foremost goal. Performance indicator has been suggested for promoting effective environmental protection. An environmental indicator can be defined as numerical value which shows insight into the state of the environment; it defines the data to be collected to measure progress and enable actual results achieved [5]. To maintain communication with the municipal many OECD (Organization for Economic Cooperation and Development) countries are becoming interested in using a reduced number of indicators picked from existing larger sets. The OECD made a shortlist of environmental indicators in 2001. These indicators have been divided into two parts for instance Pollution issues and Natural resource and asset. These indicators have been chosen from the core indicators of OECD core set of environmental indicators. The model shows indicators below at Figure 5.

\subsection{A Material Flow Analysis (MFA) Based Model}

Since Material Flow Analysis (MFA) focuses in the flow of materials in the system, it covers all aspects on its pathway within the system boundary. Industries discharge industrial wastes to the surface water. Industrial wastes convey different sort of pollutants and hazardous matter to one of the sources of water. Agricultural activities use different types of fertilizer to amend fertility of the land. The main nutrients in the fertilizer are nitrogen, phosphorus, and potassium which flow with runoff water to river as well as ground water. So, land and industries being the sources of pollutants contaminating water resources and overall natural resource. Finally 


\begin{tabular}{|c|c|c|}
\hline \multicolumn{2}{|l|}{ Ecosystem } & Socio technical System \\
\hline Natural Environment & & Industries \\
\hline Land Use & \multirow{2}{*}{ Human value } & Science and Technology \\
\hline Water Quality & & Human Environment \\
\hline \multicolumn{2}{|l|}{ Natural Resource Asset } & Socio economic \\
\hline
\end{tabular}

Figure 3. Chosen indicators for EIA based model within ecosystem and socio technical system.

\begin{tabular}{|c|c|c|}
\hline \multirow[t]{2}{*}{ Ecosystem } & \multicolumn{2}{|r|}{ Socio technical System } \\
\hline & & Industries \\
\hline Land Use & Human value & Human Environment \\
\hline Water Quality & & Socio economic \\
\hline
\end{tabular}

Figure 4. Chosen indicators for ERA based Model within Ecosystem and Socio technical system.

\begin{tabular}{|c|c|c|}
\hline Ecosystem & & Socio technical System \\
\hline Pollution & Human value & Natural Resource and asset \\
\hline
\end{tabular}

Figure 5. Chosen indicators for PI based Model within ecosystem and socio technical system.

degraded quality of water is treated at sewage and waste water treatment plant. MFA regards different keywords on its way of approach. These keywords are shown in Figure 6. Material flow analysis (MFA) works with the relationship of human values within space and time.

\subsection{A Millennium Ecosystem Assessment (MEA) Based Model}

The Millennium Ecosystem Assessment focuses particularly on the link between ecosystem services and human well-being. In order to maintain a balanced ecosystem service, wetland ecosystem should be studied precisely. Wetlands are three types according to Ramsar Convention such as 1) Inland wetlands including swamps, marshes, lakes, rivers, peat lands, etc., 2) Coastal wetlands including coral reefs, mangroves, sea grass beds, and estuaries, and 3) human made wetlands including dams, reservoirs, and fish ponds, etc. These belong to wetland ecosystem contributing to human well-being and improve the poverty. People and living organisms which live near wetland are extremely dependent on it and harmed directly by its degradation. Millennium Ecosystem Assessment provides information for any type of decision makers with an authoritative synthesis of scientific knowledge concerning the impact of changes to the world's ecosystems on human being [6]. The most important ecosystem service can be identified as fish supply and water supply that can affect human well-being. The key words for ecosystem in millennium ecosystem assessment are water quality, ecosystem structure and a biotic resource. Socio political structure, industries, science and technology, natural resource and cultural patterns belong to socio technical system. Following Figure 7 shows the model.

\subsection{A Driver Pressure State Impact Response (DPSIR) Based Model}

Driver Pressure State Impact Response (DPSIR) approach different keywords which are natural environment, natural resource asset, biodiversity, ecosystem structure and land use , socio political structure, cultural patterns, water quality, industry and socio economic within the ecosystem and socio technical system. In Driver Pressure State Impact Response (DPSIR) state changes the environmental state of the natural world with the range of stress or pressure from human activities that resulted in changes of natural environment and Ecological structure. Any kinds of pressure to the ecosystem either within biodiversity or ecosystem structure will cause larger impact to the socio technical system and was vice versa. Figure 8 represents the model.

\section{Methodology}

Multidisciplinary approach requires a rational and well-structured decision making process. One of the main difficulties is to reach a common consensus. In a wide range of environmental sector with dissimilar range of problems, environmental decision making is considered as a crucial factor. There are various types of decision 


\begin{tabular}{|c|c|c|}
\hline & \multicolumn{2}{|c|}{ Socio technical System } \\
\hline \multicolumn{2}{|l|}{ Natural Environment } & ence and Technology \\
\hline Nutrient Recycling & \multirow{2}{*}{ Human value } & Industries \\
\hline Land Use & & Natural Resource \\
\hline \multicolumn{3}{|l|}{ Water Quality } \\
\hline
\end{tabular}

Figure 6. Chosen indicators for MFA based model within ecosystem and socio technical system.

\begin{tabular}{|c|c|c|}
\hline Ecosystem & & Socio technical System \\
\hline A biotic resource asset & & Socio-Political Structure \\
\hline Ecosystem Structure & \multirow{2}{*}{ Human value } & Industries and Consumption \\
\hline Biodiversity & & Cultural Pattern \\
\hline
\end{tabular}

Figure 7. Chosen indicators for MFA based model within ecosystem and socio technical system.

\begin{tabular}{|c|c|c|}
\hline Ecosystem & \multicolumn{2}{|c|}{ Socio technical System } \\
\hline \multicolumn{2}{|l|}{ Natural Environment } & Socio-Political Structure \\
\hline \multicolumn{2}{|l|}{ Ecosystem Structure } & Industries \\
\hline Biodiversity & \multirow{2}{*}{ Human value } & Cultural Pattern \\
\hline Land Use & & Socio Economic \\
\hline \multicolumn{3}{|l|}{ Water Quality } \\
\hline \multicolumn{2}{|l|}{ Natural Resource Asset } & \\
\hline
\end{tabular}

Figure 8. Chosen indicators for DPSIR based Model within Ecosystem and socio technical system.

making tools. All of them are not appropriate in any single decision making. As environmental decision making is multi-dimensional, that's why a 2D matrix has been used in decision making in this project. In this part of study all the keywords selected in the different methods have been aggregated in a matrix. Some specific methods focus on some particular factors of social and ecological system while other methods focus on some other keywords. There are some keywords which are found in common and mostly selected among different methods. These are the most general factors influencing ecosystem and socio technical system. The main intention of this study was to recognize the most general keywords found from different approaches. A matrix has been shown in Table 2 whereas different assessment tools are accumulated in $1^{\text {st }}$ row and $1^{\text {st }}$ column shows all the keywords originated from these tools. From this matrix, it has been passable to identify the most weighting keywords. The keywords corresponding to individual approach are recognized by tick mark in Figure 9.

\section{Structure of Keywords and Indicators}

In ecosystem, the effect of water quality is related to drinking water production, wastewater treatment and ecological pollution. Mostly water recourse has direct or indirect effect on the ecosystem structure. Water quality management is certainly a complicated part which involves a number of environmental, Socio economic, technical and political factors with dynamic and interactive features. In ecosystem structure, the variety of plants is influenced by abiotic recourse. Similarly the plants are influenced by, variety and number of living organism and animal surrounding it. For that matter since ecosystem structure is related to one another, any human disturbance will have consequences for ecosystem functioning through the changes species and abiotic factors. The interactions and functions of biodiversity and ecosystems have been developed; the change of occurrence is very slow in time, which helps to species adaptation and ecosystem survival. On the other hand rapid changes within short time can have big influence on ecosystems and biodiversity of species. The disruption and destruction of the natural environment and biodiversity may occur through rapid and harmful human activities in the system. In the world incredible amounts of species aren't discovered yet by humans being .But once it is discovered, it may have positive or negative effect on the ecosystem diversity. Since humans have changed ecosystems more rapidly and there are lots of dangers and harmful human activities that may cause largest negative impact to the biodiversity. In Socio technical system, two indicators have been selected; first one is Separation and treatment of nutrients and pollutants at sewage treatment plants, (removal of phosphors and nitrogen from the WWTP) and the other one is the total percentage of agricultural Feed River with in Grossed protective zone. Each indicator deals with the effect on environment. The Separation and treatment of nutrients and pollutants at sewage treat- 


\begin{tabular}{|l|r|r|r|r|l|l|l|}
\hline $\begin{array}{l}\text { ECOSYSTEM and } \\
\text { SOCIO } \\
\text { TECHNICAL SYSTEM }\end{array}$ & LCA & ERA & EIA & MFA & $\begin{array}{l}\text { CERFORMAN } \\
\text { INDICATER }\end{array}$ & $\begin{array}{c}\text { Millennium } \\
\text { Ecosystem }\end{array}$ & DPSIR \\
\hline Nutrient recycling & & & & & & & \\
\hline Biodiversity & & & & & & $\checkmark$ & \\
\hline $\begin{array}{l}\text { Ecosystem structure and } \\
\text { composition }\end{array}$ & & & & & & $\checkmark$ & $\checkmark$ \\
\hline Abiotic resource assets & & & & & & $\checkmark$ & \\
\hline Natural Environment & $\checkmark$ & & $\checkmark$ & & & & $\checkmark$ \\
\hline water quality & $\checkmark$ & $\checkmark$ & $\checkmark$ & $\checkmark$ & & & \\
\hline Land use & & $\checkmark$ & $\checkmark$ & $\checkmark$ & & & $\checkmark$ \\
\hline Socio-political structure & $\checkmark$ & & $\checkmark$ & & & $\checkmark$ & $\checkmark$ \\
\hline Industries & $\checkmark$ & $\checkmark$ & $\checkmark$ & $\checkmark$ & & $\checkmark$ & \\
\hline science and technology & $\checkmark$ & & $\checkmark$ & $\checkmark$ & & $\checkmark$ & \\
\hline Natural resource & & & $\checkmark$ & & $\checkmark$ & $\checkmark$ & \\
\hline cultural pattens & & & & & & $\checkmark$ & $\checkmark$ \\
\hline $\begin{array}{l}\text { socio-economical } \\
\text { Aspects }\end{array}$ & & $\checkmark$ & $\checkmark$ & & & & \\
\hline Human environment & & & $\checkmark$ & $\checkmark$ & & & \\
\hline Human activity & & $\checkmark$ & & & & & \\
\hline Pollution & & & & & $\checkmark$ & & \\
\hline Energy recvery & $\checkmark$ & & & & & & \\
\hline Water production & $\checkmark$ & $\checkmark$ & $\checkmark$ & $\checkmark$ & & & \\
\hline
\end{tabular}

Figure 9. Accumulated keywords in a 2D-matrix.

ment plants will control the pollution of the area and create good healthy environment to the society. Ecosystem has four indicators, first one is a biotic resource which is shown according to WFD status for Surface water of good ecological, the second one is Ecosystem service which shows the Drinking water production and quality of surface water, the third one is recreational ecosystem that shows the service in fishing and boating of the area, (for instance the extent of fishing and boating hours). The last one is recreational ecosystem service which includes Ecosystem structure and regulatory ecosystem service of the ecology. That shows the wetland in Hectares or $\%$ of water surface area. The indicators assimilated from the matrix are enlisted in the Table 1 with corresponding detail.

Waste water and household sewage sourced from runoff water and domestic water bear contaminants which are removed in Sewage treatment or domestic wastewater treatment plant. These contaminants can be physical, chemical and biological. The main goal is to provide an environmentally-safe fluid waste stream (treated effluent) and a solid waste (treated sludge) which are prepared to dispose or reuse as fertilizer. Wastewater treatment plant contributes good effect to society by taking care of natural environment, human environment, water quality, nutrient recycling, energy recovery. Science and technology, industries, quality of surface water have varying effects on industrial, agricultural and urban development in all regions. Declination of water quality reflects in land use, it changes catchment geology and accumulation of contaminants. Surface water belongs to ecosystem service, natural resource asset, biodiversity, abiotic resource asset etc. Drinking water production covers the indicators: ecosystem service, science and technology, socio-economic and human environment etc. The increasing international interest on drinking water production is the valuation of ecosystem service. The cost of drinking water production depends on the quality of its raw water stream as input which is affected by land use, industrial disposal and human activities. Flood plains, coastal marshes, mangroves and swamps belong to wetland ecosystem which provides valuable ecosystem services. They are the source of water, fish and fiber, wildlife, flood regulation and recreation etc. This is well known that, due to population growth, increasing economic development, and excessive land use this wetland have been degraded and lost. Wetland ecosystem covers ecosystem structure, land use etc. On the other hand recreational activities such as fishing and boating, hiking along the river are the recreational ecosystem services. There are plenty of activities are observed such as car washing, small scale industries, urban farming, etc. These are dependent upon the river as a source of water as well as drainage system. 
Table 1. Selected indicators for newly proposed model within ecosystem and socio technical system.

\begin{tabular}{|c|c|c|}
\hline Service & Type & Measure \\
\hline $\begin{array}{l}\text { Separation and treatment of } \\
\text { nutrients and pollutants at } \\
\text { sewage treatment plants }\end{array}$ & Socio technical & $\%$ removal N, P4 \\
\hline Surface water of good & Abiotic resource & WFD status \\
\hline $\begin{array}{c}\text { Ecological } \\
\text { Drinking water production }\end{array}$ & Ecosystem service & Cubic meter/time \\
\hline Fishing and boating & $\begin{array}{c}\text { Recreational ecosystem } \\
\text { Service }\end{array}$ & Extent of fishing, boating hours \\
\hline Wetlands & $\begin{array}{l}\text { Ecosystem structure and } \\
\text { regulatory ecosystem service }\end{array}$ & Hectares, $\%$ of water surface area \\
\hline Grossed protective zone $-6 \mathrm{~m}$ & Socio technical & $\%$ of agricultural feed river \\
\hline
\end{tabular}

\section{Result and Discussion}

Treated water is discharged back into the Götaälv river from the wastewater treatment plant in Goteborg. In wastewater treatment, there is some yearly limit which should be maintained in the flow to the river. Annually, the average of total phosphorus and nitrogen should not exceed $0.4 \mathrm{~g} \mathrm{P} / \mathrm{m}^{3}$ and $10 \mathrm{gN} / \mathrm{m}^{3}$. In Sweden, in 2006, the removal rate of phosphorus and biological oxygen demand from the waste water have been observed around $95 \%$, removal rate for nitrogen was under $60 \%$. There are three classifications of waste water treatment process biological, chemical, physical treatments. First stage takes place in the primary stage of the treatment process. One of the mechanisms in this stage is screening, that involves using of sand catcher in order to remove solids particle and harmful organic material to environment and the equipment; then the primary settling will proceed. Next stage is biological treatment that uses to remove microorganisms, mainly bacteria that are feed on the organic matter left in the wastewater after the physical treatment. In the process nitrifying, bacteria convert ammonia into nitrate if oxygen is present. Thereafter, in anoxic conditions, denitrifying bacteria can convert nitrate into nitrogen gas. Normally, the whole process of nitrogen removal is expected to remove somewhat between $50 \%$ - 5\% of the nitrogen. At last, a polymer is added to remove the phosphorus just after the biological treatment. Finally, the secondary settling purifies the water and removes the sludge. Now the water is treated and can be discharged in Götaälv river. Phosphors are hazard material to the environment and human being but mostly it is used as fertilizer for agriculture. Phosphorus discharged from Slumpåns outlet to the River Götaälv every time .The concentration varies from year to year. In previous year as per [7] minimum phosphorus concentration that is discharged to the Götaälv river is around $70 \mu \mathrm{g} / \mathrm{l}$ in the year of 1976 to 1978 year as shown in Figure 14. On the other hand the maximum phosphorus concentration released to the river is $225 \mu \mathrm{g} / \mathrm{l}$ between the years 1987 and 1988.

The source of phosphorus in the environment can be natural source those include runoff; rainfall and manmade source include both domestic and industrial waste, runoff from agriculture land, farm animal waste and urban runoff. The 44\% concentration comes from the agriculture and this is the largest source of phosphorus. Municipal wastewater treatment plants and Industry are the second and third largest resource of phosphorus next to agriculture and it is $19 \%$ and $16 \%$ respectively the rest of the phosphors concentration come from storm water of urban area which is $5 \%$, out site waste water disposal $12 \%$ and forestry $4 \%$.

The concentration of total nitrogen is the composition of Ammonium $\left(\mathrm{NH}_{4}\right)$, nitrite $\left(\mathrm{NO}_{2}\right)$, nitrate $\left(\mathrm{NO}_{3}^{-}\right)$ and organic nitrogen. Nitrogen transport in the subsurface is a complex process. Those are part of the nitrogen cycle. The nitrogen cycle explain the movement of the element from air into the biosphere and organic compounds, then back into the atmosphere. Produced nitrates are used as key ingredients of industrial fertilizers for 
agriculture, and also have big impact on pollutants in causing the eutrophication of water system and ecosystem. The total concentration of nitrogen discharge to the Götaälv river vary in several, years, as per [7] report the maximum nitrogen concentration that are discharged to the Götaälv river is around $1180 \mu \mathrm{g} / \mathrm{l}$ in the year of 1984 to 1985 . It is observed the concentration that is discharged to the river is decreasing in the year of 1984 to 1985 . Since 1993 to 2003 the concentration of nitrogen that was discharged to the river is almost constant.

Source of Nitrogen in the environment also can be natural source those include runoff and rainfall; the man made source on the other hand include both domestic and industrial waste, runoff from agriculture land, farm animal waste and urban runoff [8]. The agriculture covers the largest source of concentration which is $44 \%$ of the total volume since nitrogen is the most common use for fertilizer. The municipal wastewater treatment plant has $24 \%$ of the total volume which makes it the second largest source for the total volume. Atmospheric disposal, industry, forestry, storm water from urban area and on-site wastewater disposal have $19 \%, 6 \%, 4 \%, 2 \%$, and 1\% of the total volume respectively.

To assess the quality of water, there are five classification schemes in Water Frame work Directive: high, good, moderate, poor and bad. "High status" means no or very low human pressure in biological, chemical and morphological conditions. It is known as "reference condition" as it is the best status which can be achieved. This reference system is type-specific, that's why they are different for different types of rivers, lakes or coastal waters. Quality assessment is based on the amount of deviation from the high status or reference conditions. For instance "Good status" indicates "slight" deviation, "moderate status" means "moderate" deviation, and so on. The ecological status considers the specific aspects of the biological elements, for example "composition and abundance of aquatic flora" or "composition, abundance and age structure of fish fauna" [9]. Two GIS maps have been produced from "vattenkarten" associated with the ecological status and the eutrophication status. In these map surface water condition have been assessed according to WFD classification scheme. In the surface water of good ecological map in Figure 10, most of the areas of surface water have satisfactory state. GoteAlvriver possesses high ecological status within Goteborg area. In eutrophication map in Figure 11, good status covers most of the water areas as well as Götaälv river.

Municipality of Sweden is responsible for water supply framework and management which includes water network, sanitation, fees determination, and management of storm water. $10 \%$ of waterworks in Sweden are depending on surface water and serving 51\% of the population [10]. Figure 12 shows the wetland status within system boundary. In Gothenburg the drinking water is supplied from two waterworks which are Lackarebäck and Alelyckan. The production capacity of each waterworks is not enough to supply water to Gothenburg according to demand by its own. Alelyckan waterworks produce about half of the total volume of drinking water delivered to the Gothenburg city. The remaining volume is provided by Lackarbäck. Götaälv and StoraDelsjö lakes are the main source of raw water of Göteborg's water supply system. In Lärjeholm, the main river intake
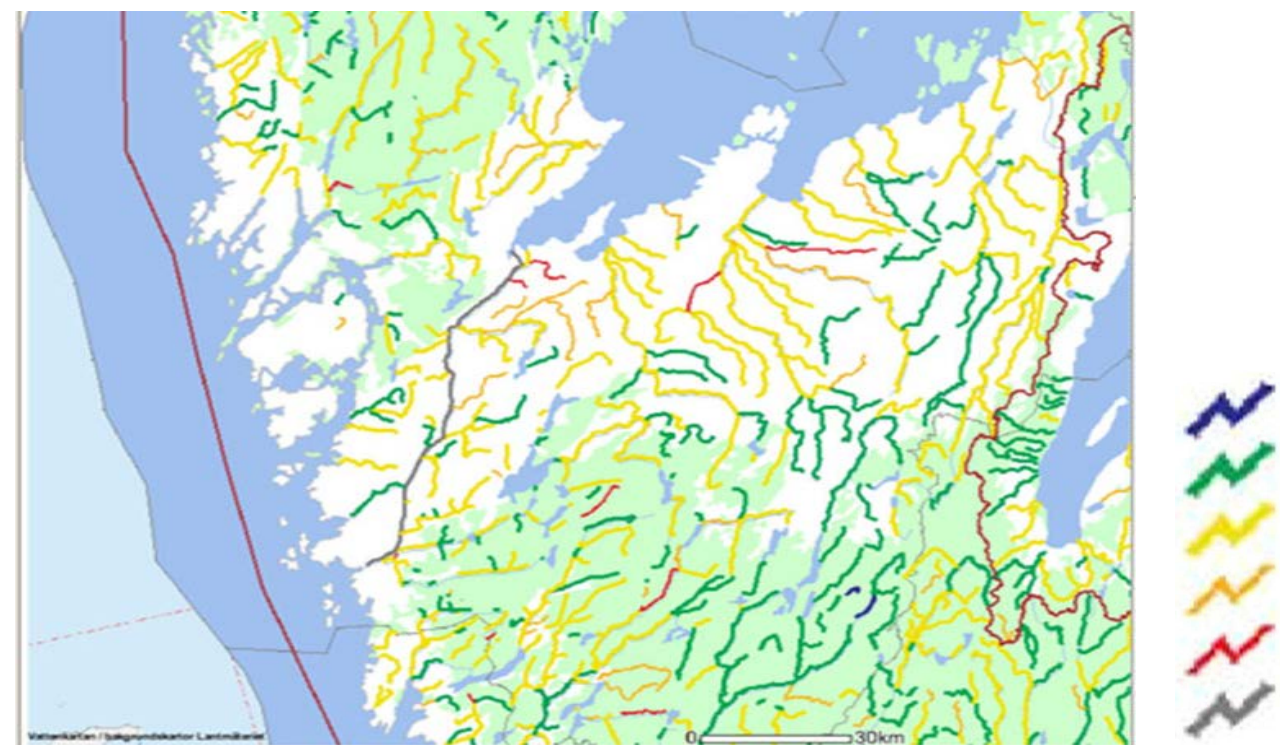

High status

Goods status

Satisfactory

Unsatisfactory

Poor status

Not classified

Figure 10. Ecological status of Götaälv river. 
Eutrophication map

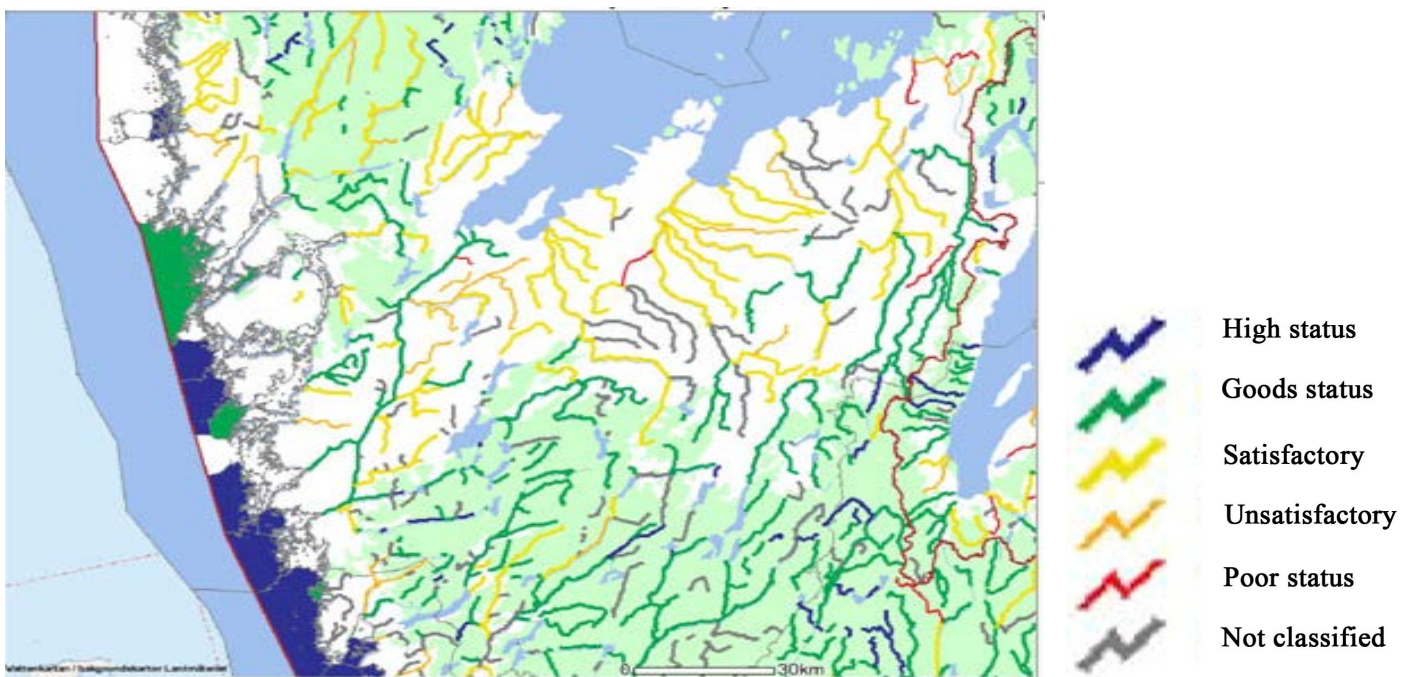

Figure 11. Eutrophication status of Götaälv river.

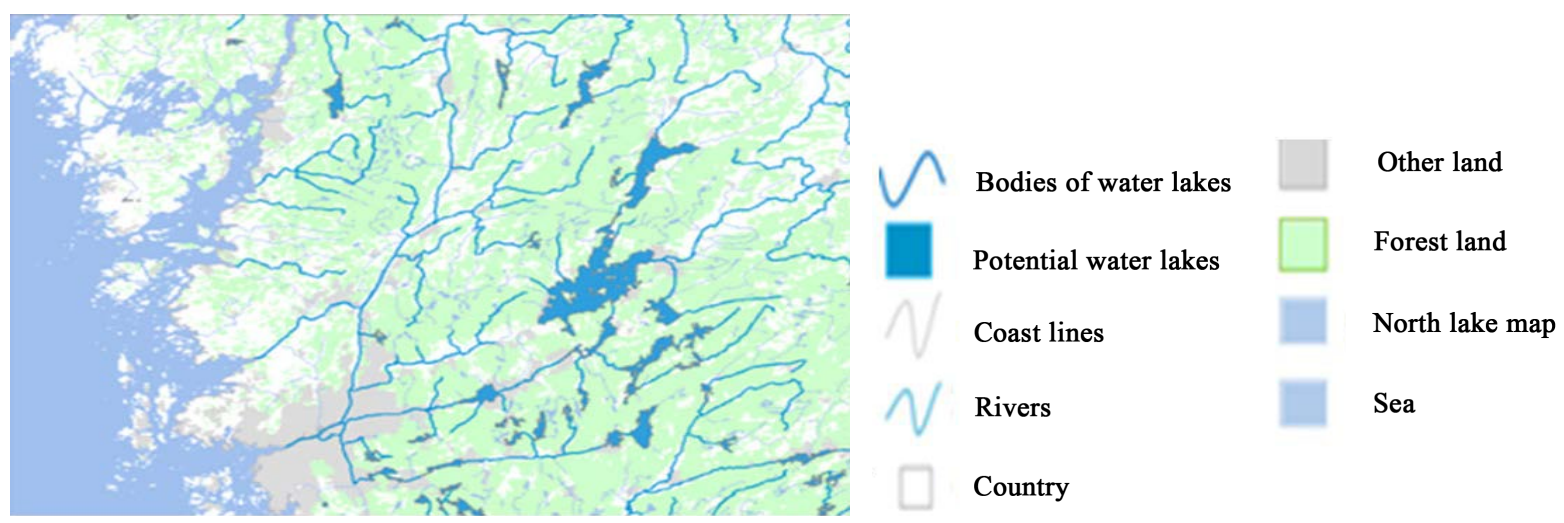

Figure 12. Wetland status of Götaälv river.

station of Alelyckan is situated. Water enters into the tunnel through the intake which is the supply of both Alelyckan waterworks and pumping station. Pumping station supplies water to Delsjö Lake from where water enters in Lackarbäck water treatment plant. If the supply from the intake is closed, then water can be delivered from Delsjö Lake for the duration of 3 weeks. StoraDelsjö Lake supplies about $3600 \mathrm{~m}^{3} / \mathrm{h}$ water to Lackarebäck water treatment plant. When the intake is stopped in supplying, then it supplies $7400 \mathrm{~m}^{3} / \mathrm{h}$ of raw water approximately to both treatment plants [11]. The total volume of drinking water is produced around 170,000 cubic meters per day as combined production from two waterworks. This volume of drinking water is supplied to half a million of people through a $1700 \mathrm{~km}$ distributed pipe system. Production of drinking water is increasing per year which has been shown in Figure 13.

Water has several uses for living beings in the earth. Götaälv river is one of the main supplies of raw water for drinking water treatment in Göteborg. Almost 700,000 people get the water supply from the river. Transportation is the other use of the river; before few years Götaälv river was the only connection to Sweden to the North Sea and the major transportation line [12]. In late 1800 year Sweden started to use the river for hydroelectric power generation, the power plant used the river as water drop and water flow for power generation. Götaälv river deliver 1.4 TWH counterparts to four present of Swedish hydropower generation and power reque and about 80,000 houses get heat from the river. The other activity in the river is fish farming; a lot of fish are taken out from the river each year. Salmon is the most affected one; around 30,000 salmon take out every year. In other way the salmon fish is growing in a smaller number, this will affect the biodiversity of ecosystem directly. Vänersborg, LillaEdet and Trollhatan which are being highlighted in Figure 14 have been identified as 
Water production in Gothenburg, total form both waterplants $\left(\mathrm{Mm}^{3}\right)$

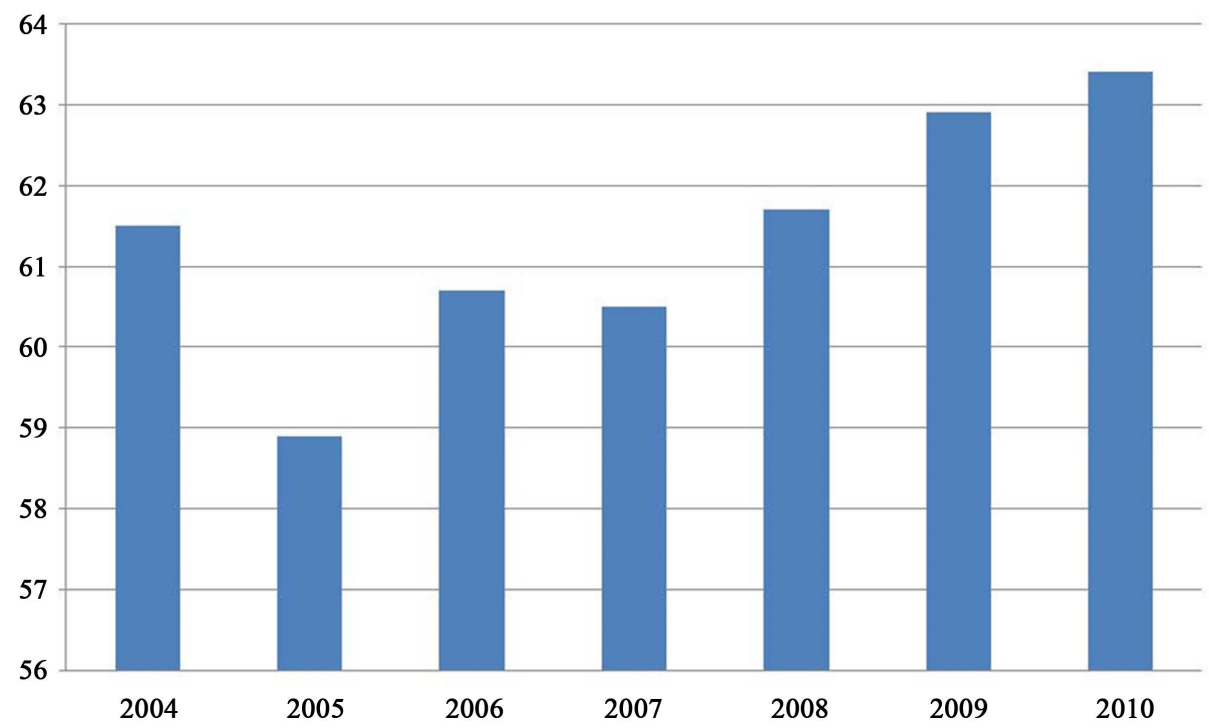

Figure 13. Water production in Gothenburg per year (Source: Göteborg Vatten).

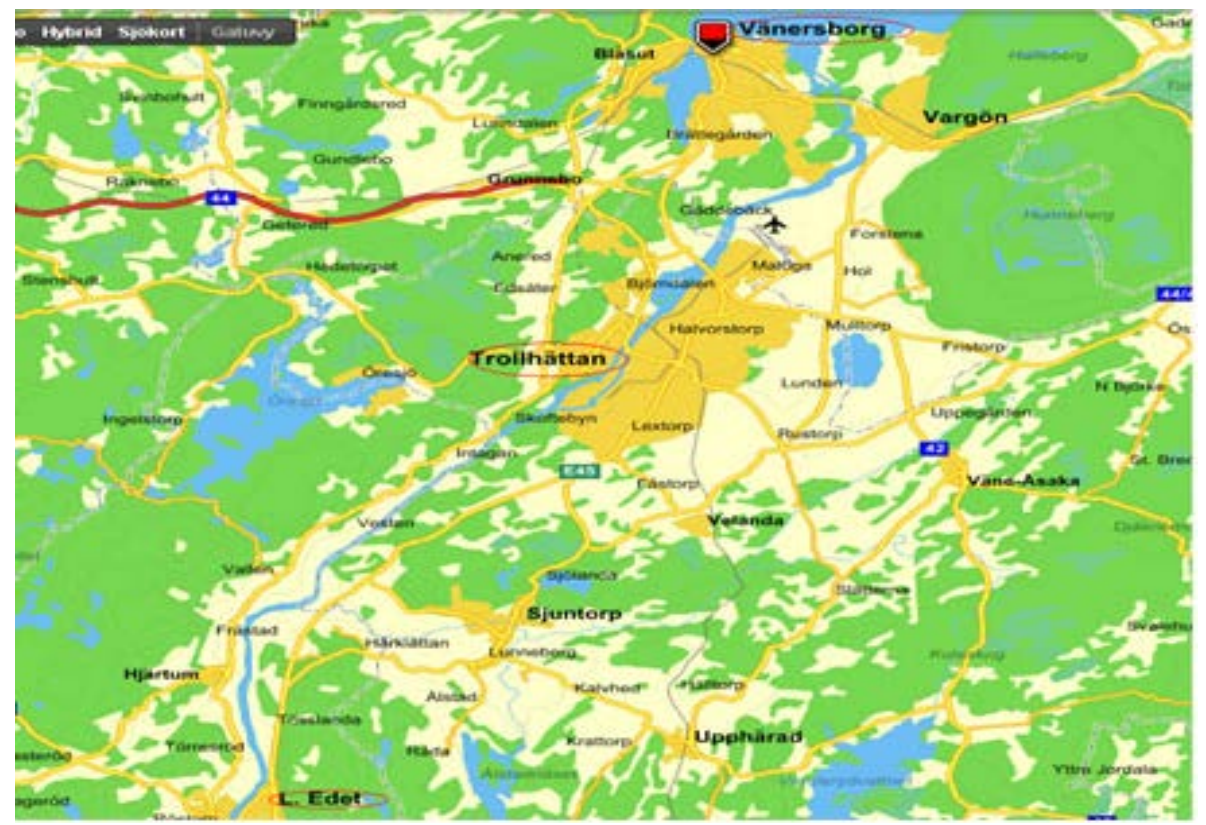

Figure 14. Recreational ecosystem service of the Götaälv river.

the most intensified zone of different activities. Some of these activities are energy supply, paper and wood products, metal production, chemical production, waste water and other. Different activities are tabled in Table 2 below along with their corresponding number.

In order to evaluate water environmental status, a newly created model of assessment has been proposed and applied within defined system boundary. This newly proposed model consists of six indicators which are categorized into socio technical system and ecosystem as well. These indicators include separation and treatment at treatment plant, gross protective zone, drinking water production, fishing and boating, percent wetland, and surface water of good ecological; represent the entire condition of water resource management and environment with regard to ecosystem services. A conceptual model regarding proposed method is shown in Figure 15. 


\section{ECOSYSTEM}

\begin{tabular}{|l}
$*$ Surface water of good \\
ecological \\
$*$ Percent of wet land \\
$* \quad$ Drinking water production \\
(Science and technology) \\
$*$ Fishing and boating \\
\hline
\end{tabular}

SOCIO TECHNICAL SYSTEM

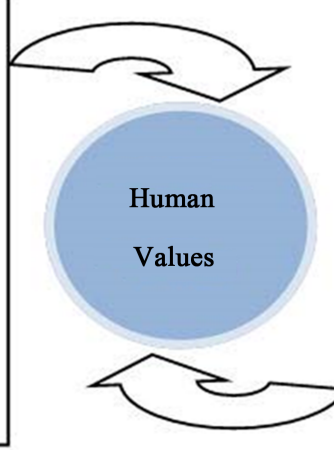
* Separation and treatment at treatment plant
* Drinking water production
* Gross protective zone

Figure 15. A conceptual models from newly proposed method.

Table 2. Different activities along the Gotaalv River at specific location.

\begin{tabular}{ccc}
\hline Activities along the river & Number & Localisation \\
\hline Energy supply & 7 & Vänersborg Göteborg \\
Paper and wood products & 3 & Vänersborg, LillaEdet \\
Metal production & 4 & Vänersborg, Trollhätan \\
Göteborg & Trollhätan \\
Wemical production & 4 & Trollhätan Göteborg \\
Waste or wastewater & 7 & Trollhätan Göteborg \\
\hline
\end{tabular}

A socio technical system includes the social aspects of people and society and technical aspects of the processes of organization [8]. Separation and treatment at sewage treatment plant, gross protective zone, and drinking water production belong to socio technical system while drinking water production also goes for ecosystem. This is because drinking water production is also ecosystem service. Natural resource assets, such as rivers, canals, marsh, lands, forests, provide ecosystem services which are very significant for human's socio technical system. Industries, transport system, treatment plants utilize these ecosystem services in order to maintain socio technical structure. Socio technical system will be unable to provide their valuable socio technical services due to degraded ecosystem services. So, socio technical system is depending on ecosystem. On the other hand, this ecosystem structure or ecosystem service is degraded by socio technical system. For instance, industries pollutes water discharging industrial wastes into the river. Rivers are the source of water providing important ecosystem service. This water goes into the water treatment plant for drinking water production. The quality of drinking water is depending on the quality of the source of water. So, socio technical services are hampered by hampering ecosystem services. So, a link between socio technical system and ecosystem is recognized. Though the systems are linked with each other, the evaluation process can be biased either environmentally or socio technically. A model of evaluation is biased intensifying particular aspects (environmental or socio technical) throughout the process. For example, according to DPSIR, resulting aggregated indicators are biased environmentally. The model regarding DPSIR clearly shows the bias. The comparison between newly proposed model and DPSIR model is showing in the Figure 16 below.

In DPSIR model generating keywords under ecosystem service such as ecosystem structure, land use, natural resource asset show the environmental bias. These ecosystem services can influence the cultural pattern which belongs to socio technical system. Natural resource is economically referred as land and raw material [12]. Depending on the natural resource of a particular region, the cultural pattern can be developed. On the other hand, due to different cultural pattern, type of land use would be changed accordingly. So, one system has an influence 


\begin{tabular}{|c|c|c|}
\hline Proposed Model & & \\
\hline \multirow{2}{*}{ Indicators } & \multicolumn{2}{|c|}{ Type } \\
\hline & Socio-technical & Ecosystem \\
\hline Ecosystem Separation and treatment at treatment plant & $\checkmark$ & \\
\hline Surface water of good ecological & & $\checkmark$ \\
\hline Drinking water production & $\checkmark$ & $\checkmark$ \\
\hline Fishing and boating & & $\checkmark$ \\
\hline Percent wetland & & $\checkmark$ \\
\hline Gross protective zone & $\checkmark$ & \\
\hline DPSIR Model & & \\
\hline Ecosystem structure & & $\checkmark$ \\
\hline Land use & & $\checkmark$ \\
\hline Natural resource asset & & $\checkmark$ \\
\hline Cultural Pattern & $\checkmark$ & \\
\hline Socio-political structure & $\checkmark$ & \\
\hline Natural (human) environment & & $\checkmark$ \\
\hline
\end{tabular}

Figure 16. A comparisons between DPSIR and the newly proposed model.

on the other. Finally influencing one another, both systems are depending on each other. To depict the relative bias, comparisons among different methods are shown in the Figure 17.

\section{Conclusion}

Biological indicators and socio technical indicators are linked visibly to each other. The quality of drinking water is depending on the quality of raw (treated in sewage treatment plant) water input into the treatment plant for drinking water production. Raw water quality depends on the quality of water supplied to the sewage treatment plant. So, the quality of raw water influences the quality of produced drinking water. To ensure the quality of raw water are to minimize bacteria, pollutants, and particulate matter from the lake. Because polluted water is the key reason of occurring public health problems. So, monitoring parameters of raw water in waste water treatment plant should be taken as an important consideration. Recreational activities along the river, for instance, fishing, boating, bathing etc., are also influencing the quality of water and finally influencing the quality of drinking water. Steps should be taken to reduce nitrogen and phosphorus that go into the water. The management of integrated water system should take into account both the ecosystem and the socio technical system. Because the link between two systems have been substantiated. That means they are not separate. LCA focus mainly on socio technical aspects whereas DPSIR is environmentally biased or focused on ecosystem. Environmental impact assessment covers both aspects of the system. Finally Figure 17 is recommended for choosing appropriate directional evolution system out of different evaluation processes enlisted there. 


\begin{tabular}{|c|c|c|}
\hline \multirow[b]{2}{*}{ Indicators } & \multicolumn{2}{|c|}{ Type } \\
\hline & $\begin{array}{c}\text { Socio } \\
\text { technical }\end{array}$ & Ecosystem \\
\hline \multicolumn{3}{|l|}{ Proposed model } \\
\hline Separation and treatment at treatment pant & $\checkmark$ & \\
\hline Surface water of good ecological & & 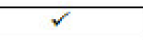 \\
\hline Drinking water production & $\checkmark$ & $\checkmark$ \\
\hline Fishing and boating & & $\checkmark$ \\
\hline Percent wetland & & $\checkmark$ \\
\hline Gross protective zone & $\checkmark$ & \\
\hline \multicolumn{3}{|l|}{ DPSIR Model } \\
\hline Natural (human) environment & & $\checkmark$ \\
\hline Natural resource asset & & $\checkmark$ \\
\hline Ecosystem structure & & $\checkmark$ \\
\hline Biodiversity & & $\checkmark$ \\
\hline Land use & & $\checkmark$ \\
\hline Water quality & & $\checkmark$ \\
\hline Socio political structure & $\checkmark$ & \\
\hline Industries & $\checkmark$ & \\
\hline Cultural patterns & $\checkmark$ & \\
\hline Socio economic & $\checkmark$ & \\
\hline \multicolumn{3}{|l|}{ LCA (Life cycle assessment) } \\
\hline Natural environment & & 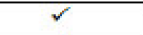 \\
\hline Nutrient recycling & & $\checkmark$ \\
\hline Water quality & & $\checkmark$ \\
\hline Industries & $\checkmark$ & \\
\hline Science and technology & $\checkmark$ & \\
\hline Energy recovery & $\checkmark$ & \\
\hline Natural resource & $\checkmark$ & \\
\hline \multicolumn{3}{|l|}{ EIA (Environmental impact assessment) } \\
\hline Natural environment & & r \\
\hline Water quality & & $\checkmark$ \\
\hline Land use & & r \\
\hline Natural resource asset & & r \\
\hline Industries & $\checkmark$ & \\
\hline Science and technology & $\checkmark$ & \\
\hline Human Environment & $\checkmark$ & \\
\hline Socio economic & $\checkmark$ & \\
\hline \multicolumn{3}{|l|}{ ERA (Environmental risk assessment) } \\
\hline Water quality & & $\checkmark$ \\
\hline Land use & & $r$ \\
\hline Human Environment & 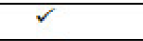 & \\
\hline Industries & $\checkmark$ & \\
\hline Socio economic & $\checkmark$ & \\
\hline \multicolumn{3}{|l|}{ MEA (Millennium ecosystem assessment) } \\
\hline Biodiversity & & $\checkmark$ \\
\hline Ecosystem structure & & $\checkmark$ \\
\hline Natural resource asset & & $\checkmark$ \\
\hline A biotic resource asset & & $\checkmark$ \\
\hline Socio political structure & $\checkmark$ & \\
\hline Industries and composition & $\checkmark$ & \\
\hline Cultural patterns & $\checkmark$ & \\
\hline \multicolumn{3}{|l|}{ MFA (Material flow analysis) } \\
\hline Nutrient recycling & & $\checkmark$ \\
\hline Natural environment & & $\checkmark$ \\
\hline Land use & & $\checkmark$ \\
\hline Water quality & & $\checkmark$ \\
\hline Industries & $\checkmark$ & \\
\hline Science and technology & $\checkmark$ & \\
\hline Natural resource & $\checkmark$ & \\
\hline
\end{tabular}

Figure 17. Comparison of selected indicators relevance for different models and strategies. 


\section{Acknowledgements}

The concept of the study documented here was evolved and shaped at the Division of WET-Water Environment Technology, Chalmers University of Technology, Sweden. And revising that, the final paper has been produced at IUBAT - International University of Business Agriculture and Technology. I would like to express my gratitude to Prof. Greg Morrison for providing valuable suggestions. Furthermore I acknowledge with appreciation Tsedy Wondmu Gebiru for her primary support at Chalmers.

\section{References}

[1] Koehler, A. (2008) Managing the Planet's Freshwater Resources. Institute of Environmental Engineering, Ecological Systems Design, ETH Zurich, Zurich.

[2] Internet Link 6, Water Pollution (2010) Point Source (Hitting Point Source). http://en.wikipedia.org/wiki/Water_pollution

[3] Miettinen, P. and Hämäläinen, R.P. (1997) How to Benefit from Decision Analysis in Environmental Life Cycle Assessment (LCA). European Journal of Operational Research, 102, 279-294.

[4] Marttunen, M. and Hämäläinen, R.P. (1995) Decision Analysis Interviews in Environmental Impact Assessment. European Journal of Operational Research, 87, 551-563.

[5] Ganoulis, J. and Simpsom, L. (2006) Environmental Risk Assessment and Management: Promoting Security in the Middle and the Mediterranean Region. Department of Civil Engineering, Aristotle University of Thessaloniki, Thessaloniki, National Science Foundation Fellow, Technology and Policy Program Massachusetts Institute of Technology, Cambridge.

[6] Millenium Ecosystem Assessment (2005) Ecosystem and Human Wellbeing: Wetlands and Water Synthesis. World Resources Institute, Washington DC.

[7] Tam, V.W.Y., Tam C.M., Zeng S.X. and Chan K.K. (2006) Environmental Performance Measurement Indicators in Construction. Building and Environment, 41, 164-173.

[8] Göta älvs Vattenvårdsförbund (2005) Fakta om Gota älv En beskring av göta alv och dess omgivning 2005.

[9] Rolf, E. and George, T. (1969) Removal of Nitrogen and Phosphorus from Waste Water. Sanford University, Sanford.

[10] Internet Link 5, Ecological Status and Intercalibr (2010) Assessment of Water Status in the WFD (Hitting on Assessment of Water Status in the WFD). http://ec.europa.eu/environment/water/waterframework/objectives/status_en.htm

[11] Pierre-Yves, T. (2010) Indicators for Water as a Range of Ecosystems and the Connection to Socio-Technical Systems. Department of Civil and Environmental Engineering Water Environment Technology, Chalmers University of Technology, Goteborg.

[12] Fox, W.M. (1995) Sociotechnical System Principles and Guidelines: Past and Present. Journal of Applied Behavioral Science, 31, 91-105. http://dx.doi.org/10.1177/0021886395311009 